\title{
A preliminary model to describe the transmission dynamics of Covid-19 between two neighboring cities or countries
}

\author{
Raúl Isea* \\ Fundación Instituto de Estudios Avanzados IDEA, Baruta, Venezuela \\ ORCID ID: 0000-0002-6318-3428. Corresponding author R. Isea (raul.isea@gmail.com)
}

\begin{abstract}
We present a mathematical model that would allow one to describe the transmission dynamics of Covid-19 between two neighboring cities or countries. This model is analyzed both analytical and numerically. It is a preliminary model because it assumes that the migration rate and the mortality rate are constant over time. Despite these simplifications, only two of the four equilibrium conditions were deduced from the system of equations proposed in this paper. Finally, we show an example the transmission dynamics between Portugal and Spain according to the cases registered before June 3, 2020.
\end{abstract}

Keywords: Covid-19, Two Countries, migration, Portugal, Spain, Model

\section{Introduction}

Currently the world is suffering from a pandemic caused by a new coronavirus (2019-nCoV) that was detected for the first time in a Chinese market in Wuhan in December, 2019. Up to June 3, more than 7 million infections have been registered worldwide and more than 400,000 have deceased according to data registered at Johns Hopkins University.

To date, a large number of mathematical models have been published to understand the transmission dynamics of Covid-19 in a given community, state, or a country [see for example 14]. However, these studies do not consider the influence that the migration effect between neighboring countries can exert, and thus be able to design public policies that best fit the cases registered across the borders.

This type of model is not new in the scientific literature, although there are few cases that analyze real data and have not been used to describe the transmission of Covid-19. In fact, one of the pioneering works was that of Ahmed et al [5] who present one of the first models with displacement between two different regions, and later generalized between different $\mathrm{n}$ patches by Sattenspiel et al [6]. In fact, Wallen and Zhao present various variants based on a SEIR and SEIRS type compartmental model [7,8]. However, it was Chen et al [9] who proposed a transmission model where people can become infected during travel. 
medRxiv preprint doi: https://doi.org/10.1101/2020.07.18.20156695; this version posted July 21, 2020. The copyright holder for this preprint (which was not certified by peer review) is the author/funder, who has granted medRxiv a license to display the preprint in perpetuity.

It is made available under a CC-BY 4.0 International license .

Unfortunately, the countries do not separate the cases of contagion by local (or community) Covid-19 and those caused by the effect of migration (or imported). This is a limitation that it is necessary to indicate in the future.

Therefore, this work presents a preliminary mathematical model that could explain the transmission dynamics of Covid-19 that moves between neighboring countries as will be explained in the next section.

\section{Mathematical model}

The model is of the compartmental type capable of describing the transmission dynamics between two neighboring cities or countries. The cities are denoted with the subscripts 1 and 2 , and we propone the following system of equations:

$$
\begin{gathered}
\frac{d S_{1}(t)}{d t}=\Lambda_{1}-\beta_{1}(t) S_{1}(t) I_{1}(t)+\beta_{21} I_{2}(t)-\gamma S_{1}(t) \\
\frac{d I_{1}(t)}{d t}=\beta_{1}(t) S_{1}(t) I_{1}(t)-\left(\gamma+c_{1}+\beta_{12}\right) I_{1}(t) \\
\frac{d S_{2}(t)}{d t}=\Lambda_{2}-\beta_{2}(t) S_{2}(t) I_{2}(t)+\beta_{12} I_{1}(t)-\gamma S_{2}(t) \\
\frac{d I_{2}(t)}{d t}=\beta_{2}(t) S_{2}(t) I_{2}(t)-\left(\gamma+c_{2}+\beta_{21}\right) I_{2}(t)
\end{gathered}
$$

where $S_{1}(t)$ and $S_{2}(t)$ represent the populations that are susceptible to contracting the virus, while the infected populations are indicated with $\mathrm{I}_{1}(\mathrm{t})$ and $\mathrm{I}_{2}(\mathrm{t})$.

This model is based on the following assumptions:

- There is no distinction between local and imported cases in each of the countries since there is no complete record in the databases available (ie., Johns Hopkins University).

- The number of cases of contagion imported from one country to another is considered to be a constant over time. It's a simplification and therefore the fraction of the population that travels from country 1 to country 2 is represented as $\beta_{12}$, while from 2 to 1 is represented as $\beta_{21}$.

- Each country has its own demographic rate and it is equal to $\Lambda_{1}$ and $\Lambda_{2}$.

- Both countries have the same natural mortality rate $(\gamma=0,00004)$.

- The mortality rates caused by the Covid-19 are represented as $c_{1}$ and $c_{2}$, and are assumed to be constant over time.

- The contagion rate in each country will be represented with the variables $\beta_{1}(t)$ and $\beta_{2}(t)$, as explained in a recent work published by Isea [4]. These variables are equal to 
$\beta_{i} /\left[\mu_{i}+I_{i}(t)\right]$ where the subscript represents each of the countries $(\mathrm{i}=1,2)$. The $\beta_{\mathrm{i}}$ and

$\mu_{\mathrm{i}}$ values are determined from a least squares adjustment of the cases of contagion registered in the John Hopkins University database.

In the next section, the system of equations proposed in the work will be analytically investigated.

\section{Analytical resolution}

The methodology required to solve the system of equations proposed in this work has been described on multiple occasions throughout various scientific works [10-14], and for this reason, only we shows the results.

Four steady-state solutions are obtained when the system of equations is solved (denoted as PC $\mathrm{i}=1$ until 4) and they are:

$$
\begin{gathered}
P C^{1}=\left[S_{1}^{*}=\frac{\Lambda_{1}}{\gamma}, I_{1}^{*}=0, S_{2}^{*}=\frac{\Lambda_{2}}{\gamma}, I_{2}^{*}=0\right] \\
P C^{2}=\left[S_{1}^{*}=\frac{A \mu_{1}+\Lambda_{1}}{\gamma+\beta_{1}}, I_{1}^{*}=-\frac{\gamma A \mu_{1}-\Lambda_{1} \beta_{1}}{\left(\gamma+\beta_{1}\right) A}, S_{2}^{*}=-\frac{\beta_{12} \gamma A \mu_{1}-\Lambda_{2}\left(\gamma+\beta_{1}\right) A-\Lambda_{1} \beta_{1} \beta_{12}}{\gamma\left(\gamma+\beta_{1}\right) A}, I_{2}^{*}\right. \\
=0] \\
P C^{3}=\left[S_{1}^{*}=-\frac{\beta_{21} \gamma B \mu_{2}-B \Lambda_{1}\left(\gamma+\beta_{2}\right)-\Lambda_{2} \beta_{2} \beta_{21}}{\gamma\left(\gamma+\beta_{1}\right) B}, I_{1}^{*}=0, S_{2}^{*}=\frac{B \mu_{2}+\Lambda_{2}}{\gamma+\beta_{2}}, I_{2}^{*}\right. \\
\left.=\frac{\gamma B \mu_{2}-\Lambda_{2} \beta_{2}}{\left(\gamma+\beta_{2}\right) B}\right]
\end{gathered}
$$




$$
P C^{4}=\left[\begin{array}{c}
S_{1}^{*}=\frac{A\left[B\left(\gamma+\beta_{2}\right)\left(\Lambda_{1}+A \mu_{1}\right)+\beta_{2} \beta_{21}\left(\Lambda_{2}-\beta_{12} \mu_{1}\right)+\beta_{21} \gamma B \mu_{2}\right]}{A B\left[\gamma\left(\gamma+\beta_{1}+\beta_{2}\right)+\beta_{1} \beta_{2}\right]-\beta_{1} \beta_{2} \beta_{12} \beta_{21}}, \\
I_{1}^{*}=-\frac{\beta_{1} \beta_{21} \gamma B \mu_{2}+\beta_{2}\left[A B \gamma \mu_{1}-\beta_{1}\left(\Lambda_{1} B-\Lambda_{2} A\right)+\gamma B\left(\gamma A \mu_{1}-\Lambda_{1} \beta_{1} \gamma\right)\right]}{\beta_{2}\left[A B\left(\gamma+\beta_{1}\right)-\beta_{1} \beta_{12} \beta_{21}\right]+\gamma A B\left(\gamma+\beta_{1}\right)} \\
S_{2}^{*}=B \frac{\mu_{2}\left[A B\left(\gamma+\beta_{1}\right)-\beta_{1} \beta_{12} \beta_{21}\right]-\beta_{2} A \gamma \mu_{1}+\Lambda_{2}\left(\gamma+\beta_{1}\right) A+\Lambda_{1} \beta_{1} \beta_{12}}{\beta_{2}\left[A B\left(\gamma+\beta_{1}\right)-\beta_{1} \beta_{12} \beta_{21}\right]+\gamma\left(\gamma+\beta_{1}\right) A B} \\
I_{2}^{*}=-\frac{\gamma A B\left(\gamma+\beta_{1}\right) \mu_{2}+\beta_{2}\left[\beta_{12} \gamma A \mu_{1}-\Lambda_{2}\left(\gamma+\beta_{1}\right) A-\Lambda_{1} \beta_{1} \beta_{12}\right]}{\beta_{2}\left[A B\left(\gamma+\beta_{1}\right)-\beta_{1} \beta_{12} \beta_{21}\right]+\gamma\left(\gamma+\beta_{1}\right) A B}
\end{array}\right]
$$

where were defined $A \equiv \gamma+c_{1}+\beta_{12}$ y $B \equiv \gamma+c_{2}+\beta_{21}$.

The next step is to determine if these values (ie., $\mathrm{PC}^{\mathrm{i}}, \mathrm{i}=1 . .4$ ) are stable over time, and for this, the Jacobian of the system of equations must be calculated, and evaluated in each of the four solutions indicated above.

The Jacobian obtained from the system of equations (abbreviated as $\mathrm{J}$ ) is equal to:

$$
J=\left[\begin{array}{cccc}
J_{11} & J_{12} & 0 & \beta_{21} \\
J_{21} & J_{22} & 0 & 0 \\
0 & \beta_{12} & J_{33} & J_{34} \\
0 & 0 & J_{43} & J_{44}
\end{array}\right]
$$

Where $J_{11}=-I_{1} \beta_{1} /\left(\mu_{1}+I_{1}\right)-\gamma, J_{21}=-I_{1} \beta_{1} /\left(\mu_{1}+I_{1}\right), J_{33}=-I_{2} \beta_{2} /\left(\mu_{2}+I_{12}\right)-\gamma$,

$$
\begin{aligned}
& J_{43}=-I_{2} \beta_{2} /\left(\mu_{2}+I_{12}\right), \\
& J_{12}=-S_{1} \beta_{1}\left(1-I_{1} /\left(\mu_{1}+I_{1}\right)\right) /\left(\mu_{1}+I_{1}\right), \\
& J_{22}=-\left[\begin{array}{l}
S_{1} \beta_{1}\left(1-I_{1} /\left(\mu_{1}+I_{1}\right)\right. \\
\end{array} /\left(\mu_{1}+I_{1}\right)-A\right], J_{34}=-S_{2} \beta_{2}\left(1-I_{2} /\left(\mu_{2}+I_{2}\right)\right) /\left(\mu_{2}+I_{2}\right) \\
& J_{44}=-\left[\begin{array}{l}
S_{2} \beta_{2}\left(1-I_{2} /\left(\mu_{2}+I_{2}\right)\right. \\
)
\end{array} /\left(\mu_{2}+I_{2}\right)-B\right]
\end{aligned}
$$


To determine if each solution is stable over time, we must evaluate Jacobian for each of the Critical Points, and later determine the eigenvalues. However, it was only possible to calculate the eigenvalues of the first two critical points $\left(\mathrm{PC}^{1}\right.$ and $\mathrm{PC}^{2}$ ) given that the last two have generated very complex analytical expressions which are difficult to analyze in this paper.

Two eigenvalues that were determined for the first critical point $\left(\mathrm{PC}^{1}\right)$ are:

$$
\frac{\beta_{2} \Lambda_{2}-\mu_{2} \gamma\left(\gamma+c_{2}+\beta_{21}\right)}{\gamma \mu_{2}}, \frac{\beta_{1} \Lambda_{1}-\mu_{1} \gamma\left(\gamma+c_{1}+\beta_{12}\right)}{\gamma \mu_{1}}
$$

The eigenvalues of the second critical point $\left(\mathrm{PC}^{2}\right)$ are:

$$
\begin{array}{r}
\frac{\sqrt{\beta_{1} \beta_{12} \Lambda_{1}\left[\beta_{1} \beta_{12}\left(\Lambda_{1}-2 \gamma \mu_{1}\right)\right]}+\beta_{1} \Lambda_{1}\left(2 \gamma+\beta_{12}\right)}{2 \beta_{1}\left[\Lambda_{1}+\mu_{1}\left(\gamma+\beta_{12}\right)\right]} \\
\frac{-\sqrt{\beta_{1} \beta_{12} \Lambda_{1}\left[\beta_{1} \beta_{12}\left(\Lambda_{1}-2 \gamma \mu_{1}\right)\right]}+\beta_{1} \Lambda_{1}\left(2 \gamma+\beta_{12}\right)}{2 \beta_{1}\left[\Lambda_{1}+\mu_{1}\left(\gamma+\beta_{12}\right)\right]} \\
\frac{\beta_{1} \beta_{12}\left(\beta_{2} \Lambda_{1}-\gamma \mu_{2} \beta_{21}\right)+\Lambda_{2}\left[\beta_{2} \beta_{12}\left(\gamma+\beta_{1}\right)+\gamma \beta_{1} \beta_{2}\right]}{\gamma\left(\gamma+\beta_{1}\right) \mu_{2}\left(\gamma+\beta_{12}\right)}
\end{array}
$$

From these values, we can deduce, for example, that $\Lambda_{1}>2 \gamma \mu_{1}$, so that the solutions are real. and the next step we shows an example between Portugal and Spain.

\section{Numerical solution}

We analyzed the number of infected cases between Portugal and Spain, denoted as 1 and 2, respectively. To do that, it is necessary to fit using the least squares method for each of the parameters of the system of equations based on the data recorded in the Johns Hopkins University up to June 3, 2020. We have preferred to adjust the data country by country because we don't have data separating the local and imported cases between these countries.

The figure 1 shows the results obtained in Portugal where the data are represents with circle and the least squared adjusted with a line. The normalized values obtained in Portugal are $\Lambda_{1}=5.540$ : $\beta_{1}=0.103, \mu_{1}=0.162$; while that the results obtained for Spain are $\Lambda_{2}=0.026,: \beta_{2}=0.027, \mu_{2}$ $=0.044$ 


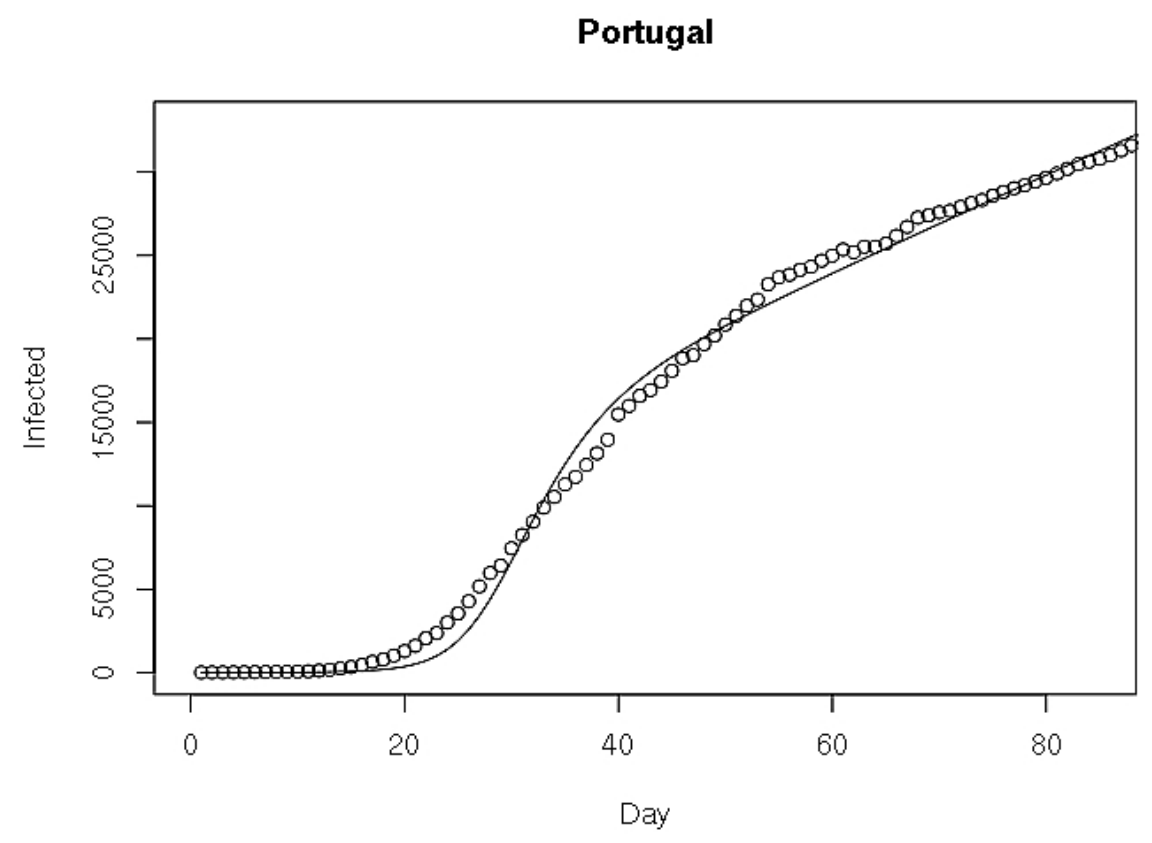

Fig 1. Cases of Covid-19 in Portugal (circle) and the results obtained by least square adjusted (line). This result was obtained with a Python program.

The figure 2 shows the vector field diagrams of the infected cases in each of the countries $\left(\mathrm{I}_{1}\right.$ versus $\mathrm{I}_{2}$ ) that were evaluated with the parameters obtained in the previous step. As can be seen in Figure 2(a), the transmission dynamics of Covid-19 between the countries when there are no imported cases $\left(\beta_{12}=\beta_{21}=0\right)$. Figure fig $2(\mathrm{~b})$ considers that there is a migration of people from Portugal to Spain $\left(B_{12}=50, B_{21}=0\right.$. These values were randomly selected. Finally, Figure 2(c) presents an extreme example where a high migration of people from Portugal to Spain is assumed highlighting the exponential growth of cases in Spain. 
medRxiv preprint doi: https://doi.org/10.1101/2020.07.18.20156695; this version posted July 21, 2020. The copyright holder for this preprint (which was not certified by peer review) is the author/funder, who has granted medRxiv a license to display the preprint in perpetuity.

It is made available under a CC-BY 4.0 International license .

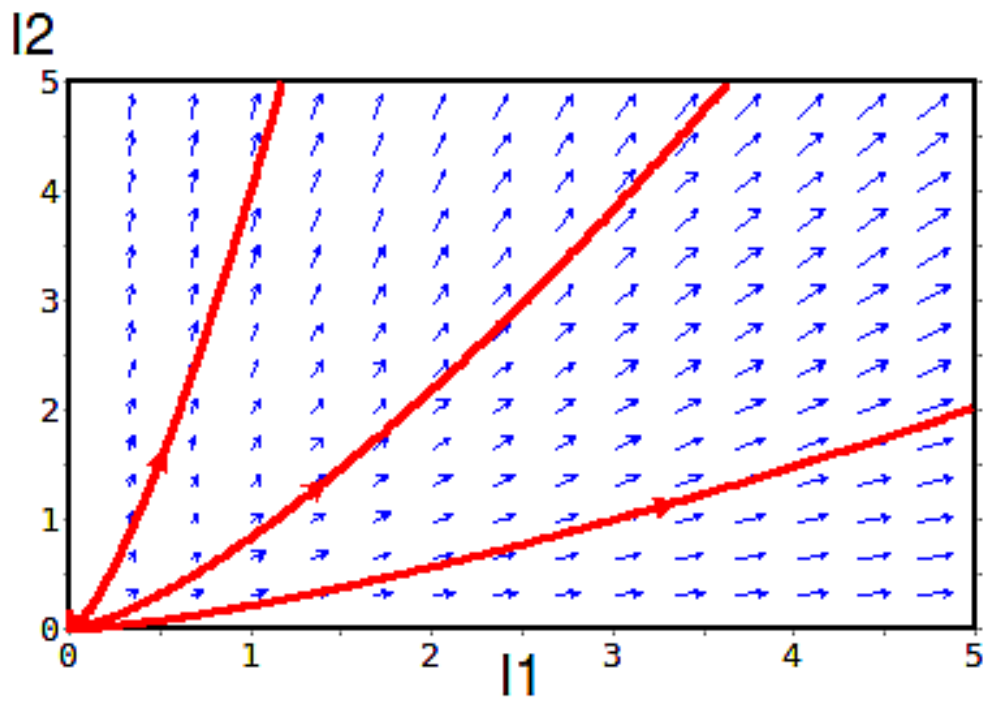

Figure 2(a). Vector field diagram of Covid-19 infected cases between Portugal and Spain (denoted as 1 and 2, respectively). In this example, we considered an initial susceptible population $S_{1}=100$ and $S_{2}=140$.

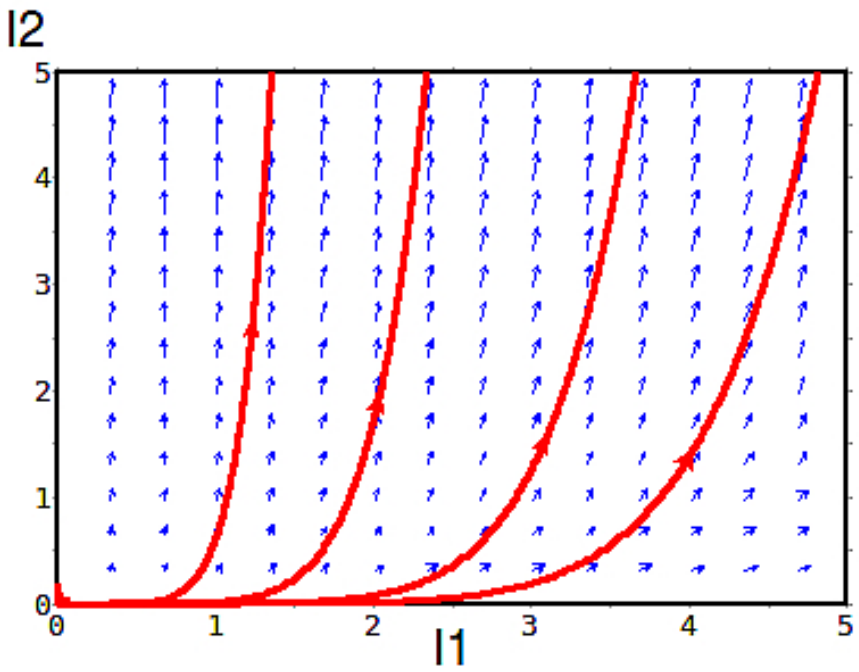

Fig 2(b). Vector field diagram where there is only a migration of imported cases from Portugal to Spain $\left(\mathrm{B}_{12}=50, \mathrm{~B}_{21}=0\right)$ where it is seen how the cases of contagion in Spain increase significantly. 


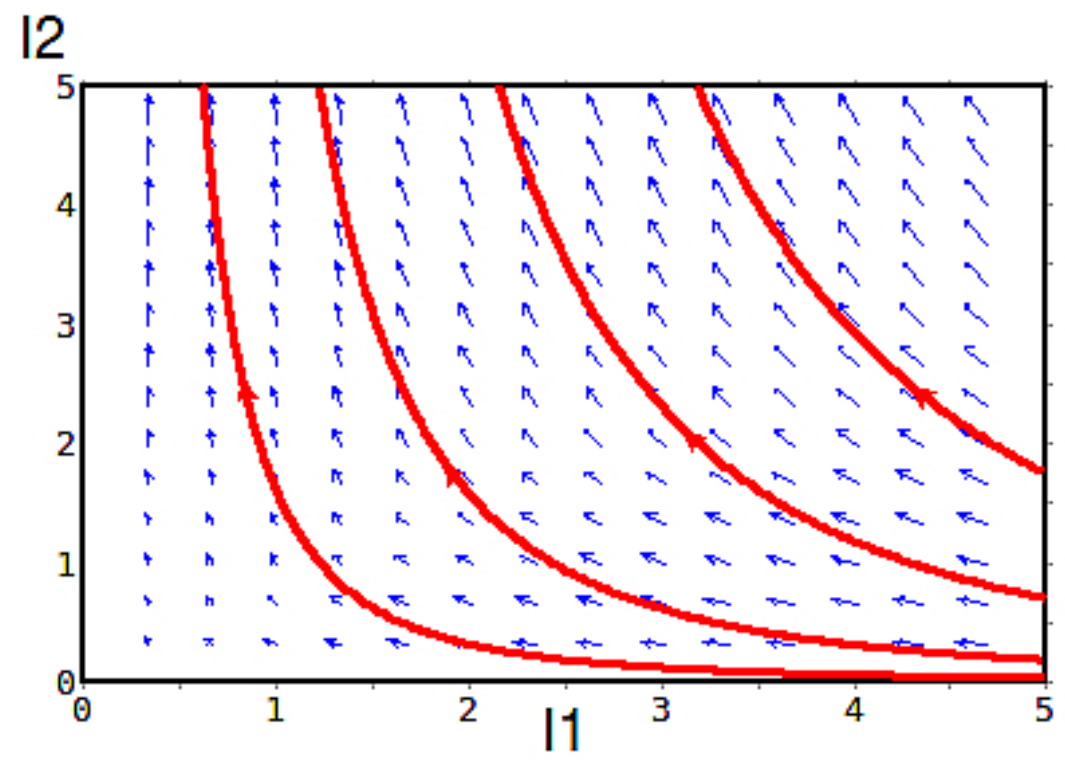

Fig 2(c). It is an extreme example where it is only considered that there could be a high migration of cases of infections that leave Portugal to Spain $\left(B_{12}=100, B_{21}=0\right)$, and we verify that Portugal presents few cases in comparison to Spain.

\section{Conclusions}

The present mathematical model proposes a system of differential equations that will allow us to understand how the transmission dynamics of cases by Covid-19 varies between two neighboring countries. This system was partially solved analytically due to the complexity of the solutions found in the work. Finally, an example of how the number of cases of Covid-19 infection between Portugal and Spain can vary is presented.

It is necessary that the countries must separate the local cases from the imported ones, and in this way be able to propose more realistic models, and in this way, for example, be able to relax or radicalize the measures at the borders between neighboring countries.

\section{Acknowledgment}

I'd like to acknowledgment to Karl E. Longreen for your comments in this manuscript. 
medRxiv preprint doi: https://doi.org/10.1101/2020.07.18.20156695; this version posted July 21, 2020. The copyright holder for this preprint (which was not certified by peer review) is the author/funder, who has granted medRxiv a license to display the preprint in perpetuity.

It is made available under a CC-BY 4.0 International license .

\section{References}

[1] Huang Y, Yang L, Dai H., Tian F and Chen K (2020) Epidemic situation and forecasting of COVID-19 in and outside China. Bull World Health Organ, E-pub. 19 March 2020.doi: http://dx.doi.org/10.2471/BLT.20.255158

[2] Peng L, Yang W, Zhang D, Zhuge C, Hong L, (2020). Epidemic analysis of COVID-19 in China by dynamical modeling. medRxiv preprint. Doi: https://doi.org/10.1101/2020.02.16.20023465

[3] Tang B, Wang X, Li Q, Bragazzi, NL, Tang S, Xian Y, Wu J. (2020) Estimation of the transmission risk of the 2019-nCoV and its implications for public health interventions. J. of Clinical Medicine. Vol 9, ID 462.

[4] Isea (2020). La dinámica de transmisión delCovid-19 desde una perspectiva matemática. Revista del Observador del Conocimiento. Vol 5(1): 15-23.

[5] Ahmed, IHI., Witbooi, PJ., and Patidar, K (2012) "Modeling the dynamics of an epidemic under vaccination in twointeracting populations". J. of Applied Mathematics, Vol 2012. ID 275902.

[6] Sattenspiel, I and Dietz, K (1995) A structured epidemic model incorporating geographics mobility among regions. Mathematical Bioscience, vol 128(1-2): 71-91

[7] Wang, WDA and Zhao, XQ (2004) An epidemic model in a patchy environment. Mathematical Bioscience, vol 190(1):97-112

[8] Wang, WDA and Zhao, XQ (2005) An age-structured epidemic model in a patchy environment. SIAM J on Applied Mathematics. Vol 65(5):1597-1614.

[9] Chen, Y., Yan, M., Xiang, Z. (2014) Transmission dynamics of a two-city SIR epidemic model with transport-related infections. J. of Applied Mathematics. Vol 2014. ID 764278.

[10] R. Isea and K.E. Lonngren (2016). A preliminary mathematical model for the dynamic transmission of dengue, chikungunya and zika. American Journal of Modern Physics and Application, 3:11-15.

[11] R. Isea and K.E. Lonngren (2017). A new variant of the SEIZ model to describe the spreading of a rumor. International Journal of Data Science and Analysis, 3(4):28-33.

[12] R. Isea and K.E. Lonngren (2013). On the mathematical interpretation of epidemics by Kermack and McKendrick. General Mathematics Notes (GMN), 19:83-87.

[13] R. Isea (2015). Una aproximación matemática de la acción de la radioterapia en células cancerosas. Revista Electrónica Conocimiento Libre y Licenciamiento, 11(6):150-160. 
medRxiv preprint doi: https://doi.org/10.1101/2020.07.18.20156695; this version posted July 21, 2020. The copyright holder for this preprint (which was not certified by peer review) is the author/funder, who has granted medRxiv a license to display the preprint in perpetuity.

It is made available under a CC-BY 4.0 International license.

[14] R. Isea. (2014). Análisis matemático de la difusión de un rumor entre dos grupos de personas. Revista Electrónica Conocimiento Libre y Licenciamiento, 8(5):85-89. 